\title{
Instruction and Exposure: How Do They Contribute To Second Language Acquisition?
}

\author{
Tej B. Shresta \\ Bilkent University
}

\begin{abstract}
Adults have access to two distinct approaches to develop their second language competence. These are instruction and exposure (Krashen 1982). Both approaches contribute to second language acquisition in their unique ways. This article describes how they contributed to the development of oral proficiency in English as a second language in mutually exclusive learning situations in Nepal.

There were 58 randomly selected subjects in the study, who came from two distinct groups. The first group was composed of people who had learned English mainly through formal classroom instruction with grammar-based approaches. The second group was composed of people who had leamed English mainly through informal contact with English-speaking people. English speech samples were collected through personal interviews and presentations based on visual materials. These oral responses were judged holistically by five independent judges. They were also analyzed by means of grammar and fluency-related errors. Data were analyzed using t-tests and correlation procedures.

The main finding was that both instruction and exposure contributed to second language acquisition in their own unique ways. The former seemed to promote accuracy and the latter fluency. For communication purposes, however, fluency seemed to be more critical than accuracy.
\end{abstract}

\section{Introduction}

Second language acquisition specialists all over the world are familiar with generations of students who, despite having spent ten or more years in classes learning a second language, emerge as nonfunctioning adults in second language performance, especially with respect to oral performance. On the other hand, countless numbers of cases can be cited in which second language leamers have learned to use the second language with ease and facility without ever going to school. They seemed to have acquired this skill virtually in the street, far from the classroom.

These apparently contradictory cases have baffled second language acquisition specialists, especially English as a second language (ESL) specialists, for quite some time, and rep-

Tej B. Shresta (Ph.D., The University of Connecticut) is Instructor in the M.A. TEFL Program at Bilkent University, Ankara, Turkey. resent two different approaches to second language acquisition. They are formal classroom instruction and informal natural exposure. In formal classroom instruction, students are generally exposed to selectively graded curriculum materials that are characterized by some form of rule isolation, error detection, and/or error correction (Krashen 1981). In informal natural exposure, however, there is no formal articulation of rules, nor are the materials selectively graded; the basic focus is on the communication of meaning (Pica 1983).

\section{Formal Versus Informal Exposure}

There seems to be no clear-cut superiority of one approach over the other as far as ESL development is concerned. One group of studies indicates that formal classroom instruction does indeed help in developing ESL proficiency. A major portion of the work in this direction came from Krashen and his associates (Krashen, Seliger, and Hartnett 1974; 
Krashen and Seliger 1975; Krashen 1976; Krashen and Seliger 1976; Krashen, Zelinski, Jones, and Usprich 1978). Similar findings regarding the beneficial effects of formal classroom instruction have been reported by others (Briere 1978; Chihara and Oller 1978; Bialystok 1979; Pica 1983; Long 1983; Billmyer 1990; and Ellis 1991).

Another group of studies points out that formal classroom instruction does not make any significant contribution to ESL development, especially when opportunities to practice English exist outside the classroom (Upshur 1968; Hale and Budar 1970; Mason 1971; Schumann 1976; Martin 1980; Kadia 1989; and Tang 1991).

The main argument of the proponents of informal exposure to the natural environment is based on their belief that language acquisition is a process of creative construction. They believe that second language learners subconsciously internalize various rules and inductively create new constructions when they attend to primary linguistic data in the natural environment (Dulay and Burt 1976).

On the other hand, proponents of formal classroom instruction argue that whereas children might be able to benefit from informal exposure to natural environment, adults must be exposed to formal classroom instruction to acquire a second language (Krashen 1981). They claim that formal classroom instruction filled with comprehensible input designed to convey meaning in a low-anxiety situation is especially beneficial for beginning adult ESL learners for whom the outside world is not prepared to provide such input for necessary intake. In fact, some other proponents of formal classroom instruction even go to the extent of stating that it is beneficial not only to beginning adult ESL learners but also to intermediate and advanced ESL learners, both adults and children alike (Long 1983). Still others state that second language learners who receive formal instruction outperform those who do not, both in terms of rate of achievement and ultimate level of achievement (Ellis 1991).

The differential effect of instruction is evi- dent when ESL proficiency is measured not only in terms of linguistic competence but also in terms of sociolinguistic competence. Billmyer (1990) reports that formal instruction in social rules helped ESL learners produce culture-relevant appropriate native-like productions, whereas similar attempts in another study by King and Silver (1993) reveal no effect of instruction.

\section{Rationale for the Present Study}

This brief review of literature on the relative effectiveness of formal instruction and informal exposure has been a mixed bag. The main problem is that the findings of these studies could not be attributed to one specific condition of learning. Krashen and his associates' subjects who learned English through formal instruction, for example, lived in the United States and had the benefit of informal exposure. Similarly, all claims made on behalf of informal exposure were based on studies that were conducted in a so-called informal natural environment where access to formal instruction or its characteristics was easily available. One could not say for sure that the observations made on the basis of such data were strictly products of formal instruction or informal exposure.

In order to really understand the unique contributions of formal instruction and informal exposure to second language development, one should study them in mutually exclusive conditions of learning. Such conditions exist in Nepal. It is one of the few countries in the world where possibilities exist for people to acquire ESL through mutually exclusive formal or informal language learning environments. One can easily identify people in Nepal whose ESL proficiency can be attributed beyond doubt to either formal language learning experience or informal natural exposure.

\section{The Study}

Therefore, this study explored the following research question:

How do formal classroom instruction and informal natural exposure contribute to the development of oral proficiency in English as 
a second language under mutually exclusive conditions of second language leaming?

In order to determine ESL oral proficiency of the subjects, a holistic scoring method, analysis of errors in grammar and structure, analysis of problems related to fluency in speech, and the extent of vocabulary development were used as criterion measures.

\section{Methods}

\section{Subjects}

Potential subjects were divided into two groups: those who had been exposed to English mainly through formal classroom instruction and those who came into contact with English either through their experience as trekking guides or through their exposure to English-speaking tourists. Some 300 potential subjects were identified for each group; of these, ten percent were chosen at random from each group as the sample population to be studied in detail.

\section{Formal Context Subjects}

The first group of subjects consisted of 29 people who learned English mainly through formal classroom instruction. They represented the formal context subjects in the study. Most of them were from various outlying districts of Nepal and were in the capital city for a brief period of about a year as a part of preservice and inservice teacher training programs. Besides this, some tenth-grade high school students from outside the city of Kathmandu were also subjects.

These formal context subjects learned their English in classes taught through grammarbased methods. They had mainly Nepalese teachers for their models of English speech. Other than an occasional use of modern cultural blessings such as movies and videos, these formal context subjects did not have exposure to an English-speaking environment by way of visiting English-speaking countries, nor did they have any chance to come in contact on a sustained basis with native English-speaking people within their own country. Their exposure to English was thus, for all intents and purposes, only in the formal English classes of their local schools. Instructional practices at these schools and the curriculum materials in use would convince an independent observer of an overriding influence of grammar-based approaches in the teaching of English in Nepal (Ministry of Education and Culture 1981).

\section{Formal Exposure Period}

Since formal context subjects included tenth-grade students through college graduates, the period of exposure to formal classroom instruction in English ranged from seven years to twelve years. Let us briefly estimate what this meant in terms of hours per year.

The average number of working days at general public schools in Nepal is about 190 days a year from Sunday through Friday, with Friday as a half working day. English is a required subject in the Nepalese schools, and it is taught for three hours a week in grades four and five, and five hours a week in grades six through ten. In other words, an average student in a general public school in Nepal receives about 115 hours a year of English instruction in grades four and five and about 150 hours a year in grades six through ten. By the end of grade ten, therefore, roughly 1,000 hours of English instruction is given to an average student who graduates from a general public school in Nepal; this instruction continues throughout the postsecondary undergraduate program in varying amounts, depending upon the field of study. The minimum is five hours a week.

This period of exposure is a very rough estimate indeed because it takes into account only instruction hours at schools and colleges in Nepal. It does not include the hours students invest in the study of English at home. Obviously, several more hours are spent in homework and test preparation on a regular basis.

\section{Informal Context Subjects}

The second group, also consisting of 29 people, represented the informal group. These informal subjects virtually picked up 
their English in the streets of Kathmandu or on trekking routes within the hills and mountains of Nepal. The majority of subjects came from the legendary Sherpa community, whose members work as mountaineering and trekking guides for foreign tourists and expedition teams.

Most of these informal subjects had no formal schooling at all. A few who had somehow managed to go to school early on in their life were either pushed out or pushed themselves out of the formal school system before long because of their need to work. Even those who had a few-years of formal schooling had no formal instruction in English because it is taught only from grade four onward in public schools of Nepal. As working adolescents and adults, these informal subjects could ill afford to go back to school to learn English. Therefore, it is fair to state that the ESL proficiency of the informal group was a product of untutored, natural exposure to English.

The informal context subjects were comparable to the formal context subjects in terms of their age level and gender mix. Among the subjects were four females who were working as domestic help in the households of American residents in Kathmandu. The majority of subjects, however, were the Sherpas who work as trekking and mountaineering guides for foreign trekkers and mountain climbers in Nepal.

\section{Informal Exposure Period}

The period of exposure to an informal language learning environment for these subjects ranged from three years to fifteen years. They were especially active during the trekking season that starts sometime in October and goes through May, with a break in winter from midDecember to mid-January. The remaining period from mid-June through September is the monsoon season in Nepal. During this period the informal context subjects have little chance to be in contact with foreign trekkers and tourists.

These informal subjects make an average of about six to eight trips a year as trekking guides for foreign tourists and trekkers in
Nepal. An average trekking trip lasts about a week to ten days, which roughly adds up to 60 working days a year. Given six hours of contact a day with English-speaking tourists on a trekking trip, this exposure amounts to 360 hours a year. In about three years, therefore, they have about 1,000 hours of exposure to English-speaking people.

As with the formal subjects, it is hard to be precise about the exact exposure period. Moreover, it is always difficult to establish a one-to-one correspondence between the formal and informal settings with regard to the quality of a given period of exposure. One year of informal exposure is not exactly the same as one year of formal exposure both in terms of quality and intensity. Even within the same exposure setting, the quality of exposure fluctuates from year to year, depending on interaction or classroom variables.

\section{Data Collection}

\section{Pilot Testing}

Before the actual data collection was started, a pilot testing was conducted on a random sample of a small group representing mutually exclusive formal and informal subjects. It was designed to determine the effectiveness of the materials and methods used in eliciting the ESL speech. During this field-testing phase of the study, it was found that very few students below grade ten from the general public schools in Nepal were able to speak English intelligibly even at the basic interpersonal communication level involving elementary vocabulary. Therefore, in the present study, the formal group of subjects included only students from grade ten through graduate level who had learned English mainly through formal classroom instruction. In other words, the period of ESL exposure for the formal group ranged from seven years to twelve years or so.

Similarly, during the field testing, it was found that very few people with fewer than three years of informal ESL exposure could use the language intelligibly for communication purposes at or beyond the sentence level. 


\section{FOREIGN LANGUAGE ANNALS-SUMMER 1998}

Therefore, the criterion of a minimum of three years of informal exposure was established. The majority of those in the informal group, however, had had five to ten years of exposure, with one man having had 15 years. This man, though, was not five times more proficient than those with three years of exposure, nor were those with ten years of exposure twice as proficient as those with five years of exposure. In fact, there were quite a few cases in which informal subjects with less exposure scored higher in the holistic judgment than those with longer exposure. This finding seemed to confirm what some believed to be the lack of linear positive correlation between informal exposure period and second language proficiency (Krashen 1982).

The pilot testing provided necessary feedback to improve upon the tools and techniques of ESL speech elicitation. Appropriate changes were made accordingly. This improved their effectiveness by way of generating free and unrehearsed samples of ESL speech that were appropriate for tapping ESL competence (Littlewood 1984).

\section{Speech Sample Elicitation Techniques}

After necessary adjustments were made, actual data collection was undertaken. Both the formal and informal subjects were interviewed individually with the help of questionnaires that were designed to gather background information as to the type and period of exposure to ESL and other socioeconomic variables. They were also presented with a series of pictures from The Ramayana and The Mahabharata, two popular sources of the Nepalese culture and tradition. The subjects were asked to tell in English about the important episodes and events presented in the pictures and describe the main characters presented there.

Every effort was made to collect an adequate sample of ESL speech from both groups of subjects. For example, the subjects were constantly reminded of the fact that there was no truth value attached to their description of the events presented in the pictures so that they would feel free to express whatever they liked. Moreover, it did not require any techni- cal know-how or other extralinguistic abilities on the part of the subjects to respond to the pictorial presentation. Since the writer himself was the interviewer, there was no problem in explaining the purpose of the study in Nepali and preparing the subjects for the interview. All the interviewer was interested in was the collection of adequate samples of ESL speech from the subjects, and he would continue to reinforce positively whenever they made an attempt to speak freely without hesitations. As a matter of fact, in order to lower such negative feelings as apprehension, anxiety, nervousness, and tension, most of the interviews were conducted in a relaxed atmosphere at a corner or cubicle of a bar or restaurant in Kathmandu.

In this way, speech samples were collected and preserved on cassette tapes. They were later analyzed to investigate if there were significant differences between the formal and informal subjects in their ESL proficiency.

\section{Data Analysis}

The speech samples were first analyzed holistically by a team of five independent judges who were educated Americans. Four of them had Ph.D. degrees and the remaining one had a master's degree, teaching ESL. They based their judgments on their overall impression of the individual speech samples, each about five minutes long, which were randomized between subject group representatives in order of presentation for scoring.

Prior to scoring the speech samples, all the judges went through a practice session that lasted until they were fully confident with, and unanimous in the use of, the scoring criteria that was somewhat similar to the Foreign Service Institute scale. The criterion scale emphasized the use of language as a tool of communication. The criteria were developed on a five-point scale, with one being poor and five being excellent (see Appendix A).

After the holistic scoring of each speech sample by the five independent judges, a holistic mean was computed for each subject by way of averaging the five holistic scores. In order to address the issue of reliability of the 
holistic sconing method, a correlation matrix among the five raters was computed, which is presented below:

\begin{tabular}{|c|c|c|c|c|}
\hline & $\begin{array}{l}\text { orrelatio } \\
\text { timating }\end{array}$ & $\begin{array}{l}\text { TABLE } \\
\text { 18 Across } \\
\text { the Inter } \\
\text { Score }(\mathbf{N}\end{array}$ & $\begin{array}{l}1 \\
\text { Five Rat } \\
\text { ater Rel } \\
58)\end{array}$ & $\begin{array}{l}\text { rs for } \\
\text { ability }\end{array}$ \\
\hline $\mathrm{R} 2$ & $\begin{array}{c}\text { R1 } \\
0.6689 \\
(0.0001)\end{array}$ & $\mathrm{R} 2$ & R3 & $\mathrm{R} 4$ \\
\hline R3 & $\begin{array}{c}0.6144 \\
(0.0001)\end{array}$ & $\begin{array}{c}0.7017 \\
(0.0001)\end{array}$ & & \\
\hline R4 & $\begin{array}{c}0.5280 \\
(0.0001)\end{array}$ & $\begin{array}{c}0.6360 \\
(0.0001)\end{array}$ & $\begin{array}{c}0.7256 \\
(0.0001)\end{array}$ & \\
\hline $\mathrm{R} 5$ & $\begin{array}{c}0.4808 \\
(0.0001)\end{array}$ & $\begin{array}{c}0.5542 \\
(0.0001)\end{array}$ & $\begin{array}{c}0.6579 \\
(0.0001)\end{array}$ & $\begin{array}{c}0.8970 \\
(0.0001)\end{array}$ \\
\hline
\end{tabular}

Note: Probabilities are shown in parentheses.

The correlation coefficients among the raters ranged between .48 and .90 , which were all significant $(p<.01)$. The average intercorrelation coefficient among the five raters was .67, calculated by the Z-transformation method. The standardized item alpha analog for interrater reliability of the average score across five raters using the Spearman-Brown method approached .91 .

\section{Results}

After the interrater reliability was established, speech samples were analyzed to determine if there was any significant difference in ESL proficiency between the two groups of subjects who leamed English in two different ways. A t-test based on their holistic mean scores, as measures of ESL oral proficiency, was computed. The results are presented in Table 2:

\section{TABLE 2}

\section{T-Test of the Holistic Mean Scores}

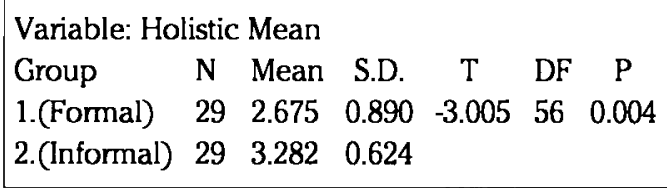

The t-test on the holistic mean scores indicated that there was a significant difference between the two groups $(p<.01)$. The informal group secured a significantly higher holistic mean score than the formal group. In the opinion of the five educated American judges who spoke standard English, the informal subjects were better than the formal subjects in their ESL oral proficiency.

This result was further analyzed in specific details. What made five judges judge the way they did? It was decided to supplement the judges' subjective scoring with some sort of objective measures. First, an error analysis on grammar and structural problems was undertaken. It consisted of calculating the number of subject-verb disagreements, e.g., "He go;" adjective-noun disagreements, e.g., "Two book;" omissions of copulas, e.g., "He going;" and word-order problems, e.g., "English speak many people." Based on a combined score on these four problem areas, a composite score on grammar and structure problems was obtained for each subject in both the formal and informal groups. The mean difference between the two groups was analyzed using a ttest and the results are presented below:

\section{TABLE 3}

\section{T-Test of the Composite Mean Scores On Grammar and Structure Problems}

Variable: Grammar and Structure Problems

Group N Mean S.D. T DF P

$\begin{array}{lllllll}\text { 1.(Formal) } & 29 & 3.134 & 2.263 & -3.0918 & 56.0 & 0.0031\end{array}$ 2.(Informal) $29 \quad 5.172 \quad 2.726$

The t-test indicated a statistically significant mean difference between the two groups on grammar and structure problems $(p<.01)$. 
The composite mean score of the formal group was significantly less than that of the informal group, which indicated that the formal subjects made significantly fewer errors than the informal subjects did on grammar and structure.

Despite this apparent superionity of the formal group of subjects in terms of their ability to use grammar and structure correctly, what could be the reason for their receiving lower scores on overall oral proficiency in ESL from the judges? The speech samples of both formal and informal subjects were further analyzed. This time it was decided to analyze the samples in terms of fluency-related problems, which consisted of audible and inaudible pauses, hesitations, repetitions, and fragmentations in speech. A composite score on fluency-related problems was obtained for each subject in both the formal and informal groups by combining scores from each of the three fluency-related problems. A t-test was used to determine if any significant mean difference existed between the two groups with respect to this issue. The results are presented below:

\section{TABLE 4}

\section{T-Test of the Composite Mean Scores On Fluency-Related Problems}

Variable: Fluency-Related Problems

\begin{tabular}{|lllrccc} 
Group & $\mathrm{N}$ & Mean & S.D. & $\mathrm{T}$ & $\mathrm{DF}$ & $\mathrm{P}$ \\
1.(Formal) & 29 & 19.172 & 12.464 & 2.975 & 56.0 & 0.004 \\
2.(Informal) & 29 & 11.034 & 7.844 & & & \\
\hline
\end{tabular}

The t-test on problems related to fluency in speech also yielded a significant mean difference $(p<.01)$. The mean score of the formal subjects on the fluency-related problems, which consisted of unwanted pauses, repetitions, and fragmentations, was significantly higher than that of the informal group. On the other hand, the formal group had significantly lower mean scores than the informal group on grammatical and structural errors ( $p<.01)$. This suggests that the formal group suffered more from fluency-related problems than the informal group, and that the latter had more grammatical and structural problems than the former.

How do these problems affect oral proficiency in ESL? As stated earlier, in the opinion of the five judges, the informal group was significantly better than the formal group in its ESL oral proficiency. This indicates that for effective communication purposes, the ability to speak English fluently is more critical than the ability to speak grammatically correct but halting English sentences. In the opinion of the five judges, fluency is more important than accuracy in communicating an oral message. This is illustrated by the following correlation table:

\begin{tabular}{|c|}
\hline \multicolumn{1}{|c|}{ TABLE 5} \\
Correlation Between the Holistic Mean \\
Score and Composite Mean Scores \\
On Grammar and Fluency-Related \\
Problems (N=58) \\
Holistic Mean $\quad$ Grammar Problems \\
Grammar -0.0246 \\
problems $(0.8545)$ \\
\begin{tabular}{ll} 
Fluency -0.6339 \\
problems (0.0001) $\quad-0.1060$ \\
\hline Note: Probabilities are shown in parentheses.
\end{tabular} \\
\hline
\end{tabular}

As the table indicates, there was no significant correlation between the holistic mean score and the composite mean score on grammatical and structural errors (subject-verb disagreements, adjective-noun disagreements, problems with "to-be" verbs, and word order problems). In other words, errors in grammar and structure did not significantly disrupt or break down the communication between the speaker and listeners. What seemed to disrupt the communication was the lack of fluency in ESL speech because there was a significant negative correlation between the scores on the fluency-related problems and the holistic mean score $(r=-.63, p<.01)$.

The data analysis also indicated that there was a significant correlation between vocabulary development and the holistic mean score $(r=.42, p<.01)$. In order to measure the extent of vocabulary development in English, a 
word count of different content words in a 100-word speech sample was undertaken. Those subjects who had higher scores in the word count were also found to have received higher holistic mean scores from the judges. Earlier, it was found that there was no significant correlation between the score on grammar and structure problems and the holistic mean score.

\section{Discussion}

In the final analysis, the study seems to throw some additional light of support on Krashen's input hypothesis, which states that second language acquisition is a function of comprehensible input designed to convey messages in low-anxiety situations (Krashen 1985). The formal subjects' preoccupation with the form of the language at the expense of the meaning conveyed not only hindered the smooth flow of their ESL speech but also disrupted the line of their communication. When the focus was on the form of the language, their anxiety level heightened because of their concern for grammatical accuracy. As a result, ESL speech suffered from unwanted pauses, hesitations, repetitions, false starts, and fragmentations that inevitably annoyed the judges and might have thus contributed to their lower scores.

On the other hand, the informal subjects' concern for the meaning of the language conveyed rather than the form it carried not only relieved them of the anxiety and tension that caused the fluency-related problems for the formal subjects but also facilitated their flow of speech and thereby improved their communication. This probably was the reason for their scoring higher grades from the judges. Secondly, a good stock of the ESL vocabulary was more useful than having a good command over grammar and structure with poor vocabulary for basic communication purposes.

\section{Conclusion}

This study suggests that formal and informal language learning environments seem to contribute to second language acquisition in their own unique ways. The formal grammar-based classroom instruction seemed to promote accuracy and the informal natural exposure based on personal contact and meaningful interaction with English-speaking people seemed to promote fluency. An analysis of the opinion of the five independent judges indicated that, for basic communication purposes, fluency in ESL speech was considered to be more critical than accuracy in grammar.

\section{ACKNOWLEDGMENTS}

I would like to thank Theodore S. Rodgers, Patricia N. Sullivan, and two anonymous reviewers for their careful reading of the manuscript and insightful comments on it; however, all the weaknesses and omissions are mine alone.

\section{REFERENCES}

Bialystok, Ellen. 1978. "A Theoretical Model of Language Learning." Language Leaming 28: 69-83.

Billmyer, Kristine. 1990. "I Really Like Your Lifestyle: ESL Learners Learning How to Compliment." Penn Working-Papers in Educational Linguistics 6: 31-48.

Briere, Eugene J. 1978. "Variables Affecting Native Mexican Children's Learning Spanish as a Second Language." Language Leaming 28: 159174.

Chihara, Tetsuro, and John W. Oller, Jr. 1978. "Attitudes and Proficiency in EFL: A Sociolinguistic Study of Japanese Speakers." Language Leaming 28: 55-68.

Dulay, Heidi C., and Marina K. Burt. 1976. "Creative Construction in Second Language Learning and Teaching." Language Leaming, Special Issue Number 4: 65-79.

Ellis, Rod. 1991. Instructed Second Language Acquisition. Oxford: Basil Blackwell.

Hale, Thomas, and Eva Budar. 1970. "Are TESOL Classes the Only Answer?" Modern Language Journal 54: 487-92 .

Kadia, Kayiba. 1989. "The Effect of Formal Instruction on Monitored and on Spontaneous Naturalistic Interlanguage Performance: A Case Study." TESOL Quarterly 22: 509-15.

King, Kendall A., and Rita-Elaine Silver. 1993. "'Sticking Points:' Effects of Instruction on NNS Refusal Strategies." Penn Working-Papers in Educational Linguistics 9: 47-82. 
Krashen, Stephen D. 1976. "Formal and Informal Linguistic Environments in Language Acquisition and Language Learning." TESOL Quarterly 10: $157-68$.

1981. Second Language Acquisition and Second Language Learning. Oxford: Pergamon Press.

1982. Principles and Practice in Second Language Acquisition. Oxford: Pergamon Press. 1985. The Input Hypothesis: Issues and Implications. New York: Longman, Inc.

Krashen, Stephen D., Herbert W. Seliger, and Dayle Hartnett. 1974. "Two Studies in Second Language Learning." Kritikon Litterarum 3: 220-28.

Krashen, Stephen D., and Herbert W. Seliger. 1975.

"The Essential Contributions of Formal Instruction in Adult Second Language Learning." TESOL Quarterly 9: 173-83.

1976. "The Role of Formal and Informal Linguistic Environments in Adult Second Language Learning." Intemational Joumal of Psycholinguistics 3: 15-21.

Krashen, Stephen D., Carl M. Jones, Stanley J. Zelinski III, and Celia Usprich. 1978. "How Important Is Instruction?" English Language Teaching Journal 32: 257-61.

Littlewood, William. 1984. Foreign and Second Language Learning: Language Acquisition Research and its Implications for the Classroom. Cambridge: Cambridge University Press.
Long, Michael H. 1983. "Does Second Language Instruction Make a Difference? A Review of Research." TESOL Quarterly 17: 359-82.

Mason, Charles. 1971. "The Relevance of Intensive Training in English as a Foreign Language for University Students." Language Leaming 21: 197204.

Ministry of Education and Culture, Curriculum and Textbook Development Center. 1981. Revised English Cumiculum for Lower Secondary and Secondary Level. Sano Thimi, Nepal: Janak Educational Materials Center, Ltd.

Pica, Teresa. 1983. "Adult Acquisition of English as a Second Language Under Different Conditions of Exposure." Language Learning 33: 465-95.

St. Martin, Gail M. 1980. "English Language Acquisition: The Effects of Living with an American Family." TESOL Quarterly 14: 388-90.

Schumann, John. 1976. "Second Language Acquisition: The Pidginization Hypothesis." Language Learning 26: 391-408.

Tang, Gladys. 1991. "Do Learning Environments Make a Difference? A Study on the Acquisition of the English Interrogatives by Three Types of Cantonese Classroom Learners." CUHK-Papersin-Linguistics 3: 49-82.

Upshur, John A. 1968. "Four Experiments of the Relation Between Foreign Language Teaching and Learning." Language Leaming 18: 111-24.

\section{APPENDIX A}

\section{Instructions for Holistic Scoring}

Holistic scoring is a method designed to assess the "overall" effectiveness of a written or oral performance. In the present study, we are concerned with judging the oral performance of a group of people who have learned English as a second language in Nepal. The oral performance is judged on the basis of speech samples that were collected through a picture description task. The pictures were related to The Ramayana and The Mahabharata, the two most popular religious scriptures in the country.

As a judge, you are kindly requested to listen to each speech sample attentively and score each of those samples holistically. The main assumption of the holistic scoring is that each of the factors involved in the oral skill is related to all the other factors and no one factor can be separated from the others.

As you listen to the tape, you will notice that the investigator is frequently expressing some kind of favorable remark such as "that's good," "that's interesting," "that's very true," or a simple hum of positive expression. They were simply designed to keep the speaker talking and in no way implied that the message was successfully conveyed. As a judge, it is up to you to de termine whether a message was conveyed or not. 
A set of scoring criteria is available for your reference. Read the criteria carefully and refer to it whenever necessary. Score each sample immediately after you finish listening to it. Unless there is some technical problem, please avoid the temptation of listening to the samples repeatedly to justify the scoring in terms of specific errors. The overall concem should be on the communication of the message. A detailed description of the scoring criteria along with the points they carry is given below:

\section{Criteria}

A sample that clearly communicates a message and compares favorably with the oral proficiency of an educated native English speaker in terms of pronunciation, intonation, fluency, vocabulary, grammar, and structure.

A sample that contains only minor inaccuracies in pronunciation, intonation, fluency, vocabulary, grammar, and structure and these inaccuracies in no way interfere with the communication of the message.

A sample in which communicability is affected due to inaccuracies in one or more of the following areas: pronunciation, intonation, fluency, vocabulary, grammar, and structure. These deficiencies may cause an occasional recourse to the use of the native language, audible and inaudible pauses between words and phrases, and some hesitation in speech.

A sample in which communication breaks down due to apparent deficiency in pronunciation, intonation, fluency, vocabulary, grammar, and structure. It also contains one or more of the following deficiencies: hesitations, repetitions, long pauses between words and phrases, and frequent use of the native language.

A sample in which the message is barely communicated due to serious gaps and deficiencies in pronunciation, intonation, fluency, vocabulary, grammar, and structure. It also contains more of the deficiencies listed earlier for the sample carrying a score of 2 , which include hesitations, repetitions, long audible and inaudible pauses between words and phrases, and frequent and prolonged use of the native language.

\section{Point}

5

4

3 


\section{Subscription Rates - Foreign Language Annals}

Foreign Language Annals is published four times each year, quarterly. The 1999 subscription rate for Domestic institutions is $\$ 70.00$. The rate for International subscriptions (including subscribers in Canada and Mexico) is $\$ 80.00$. Subscriptions are on a calendar year only (January 1st-December 31st).

Your subscription to Foreign Language Annals entitles you to subscribe to the ACTFL Newsletter at the reduced member rate of $\$ 25.00$ (Domestic) or $\$ 30.00$ (International) per year.

ACTFL also offers multiple-year subscriptions to Foreign Language Annals. The rates are listed below. You may elect to have a one-year subscription or to subscribe for either two or three years; please indicate your preference.

In order to initiate your subscription to Foreign Language Annals, please return this form with your payment as soon as possible.

Please indicate amount and form of payment below:

Domestic Subscription:

$\square 1$ year $\$ 70.00$

$\square 2$ years $\$ 130.00$

$\square 3$ years $\$ 195.00$

$\square$ ACTFL Newsletter - $\$ 25.00$

(with Domestic Subscription)
International Subscription:

$\begin{array}{lr}\square \text { 1 year } & \$ 80.00 \\ \square \text { 2 years } & \$ 150.00 \\ \square \text { 3 years } & \$ 225.00\end{array}$

$\square$ ACTFL Newsletter - $\$ 30.00$

(with International Subscription)

Payment enclosed.

$\square$ Purchase Order \# is coming.

Renewed through agency.

(Please Type or Print Clearly)

Subscriber:

Attention:

Address:

City: State Zip

Telephone: 


\section{In a C lass b y It se lf :}

\section{Focus on Instruction}

12

he special focus in this issue involves two often-neglected areas of language teaching: (1) the use and abuse of true and false cognates; and (2) the teaching of idioms and other forms of figurative language. The article by Frantzen explores the problems and promises of teaching cognates within the typical foreign language program. Cooper stresses the importance of including idioms in the foreign language curriculum, and he presents specific examples of how to teach them.

Frantzen notes that false cognates are not reliably false. This fact can prove demoralizing to students as when, in the Spanish class, they are taught that pregunta should be used instead of cuestion-only to find later on that the latter noun is indeed used in contexts in which the English word "question" appears (e.g., "It is a question of values"). Frantzen presents a wide variety of examples of how to deal with truly false and unreliably false cognates in the classroom situation.

Cooper emphasizes the importance of teaching idioms and other forms of figurative language. He cites research to document that a remarkably high percentage of adult discourse involves the use of idiomatic expressions. He identifies a hierarchy of types of idiomatic expressions, ranging from those that are easy to learn in a foreign language to those that are extremely difficult. He includes a wide variety of suggested techniques for teaching idiomatic expressions and figurative language.

As in past issues of Foreign Language Annals, readers are urged to consider submitting articles that are oriented to classroom application for possible publication in this section.

-Frank M. Grittner, Editor 